\title{
A TEMPORALIDADE NA POESIA DE MANUEL BANDEIRA
}

Flávio Loureiro Chaves

O tema da brevidade da vida se faz presente em tôda a evolução da literatura ocidental: podemos encontrá-lo em Horácio como em Rilke, em Camões e nos poetas modernistas. Através dêle, a literatura enfrentou uma questão que reside na própria raiz da tradição filosófica do Ocidente - o conceito de tempo. Comenta Raul Castagnino: «La idea del transcurrir vital, en el común de los mortales, se asocia con la meditación acerca de las fronteras de la temporalidad o con el enigma del Tiempo; en filósofos o artistas asume honduràs ontológicas (... . .» ${ }^{1}$ Os românticos do século XIX transformaram a questão em objetivo primordial, tema obsessivo que condicionou a própria maneira de ser do homem da época. O Romantismo representou um dos momentos decisivos na estruturação da mentalidade moderna; e é Arnold Hauser quem nos oferece um roteiro seguro para a sua interpretação: «La imagen del mundo hasta el Romanticismo era fundamentalmente estática, parmenidea y ahistórica (...). La idea de que nosotros y nuestra cultura estamos en un eterno fluir y en lucha interminable, la idea de que nuestra vida espiritual es un processo y tiene un earácter vital transitorio, es un descubrimiento del Romanticismo y representa su contribución más importante a la filosofia del presente». ${ }^{2}$ De fato, é na literatura romântica que o desenraizamento e a solidão se convertem em experiência definitiva do homem, encontrando expressão na tópica da vida breve que se constitui em verdadeiro programa literário. Sob

I - Habl U. Castagnino, Tiempo y Expresión Literaria. Buenos Aires, 1007, Igditorial Nova, p. 10.

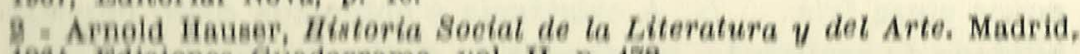

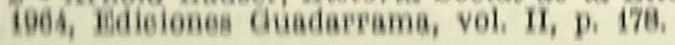


a impressão de um mundo oscililante, onde todos os valôres são relativos, a vida é curta; ràpiodamente consumida no tédio da oolidilo, como em Ālvares de Azevedo:

Eu deixo a vida co"mo deixa o tédio

Do deserto, o poento $o$ caminheiro

- Como as horas de um longo pesadelo

Que se desfaz ao doobre de um sineiro.

Pага não falarmos, ainda no mesmo poeta, daquela aspirậิo enunciada no Se eu mo rresse amanhã, que resume, em Altima instância, tôda a sensaцção de fugacidade e consciência do aftemero que lhe invadia a , existência:

Mas essa dor da viida que devora

A âsia de glória, $\varrho$ dolorido afã...

$A$ dor no peito enrudecera ao menos

Se eu morresse am anhã!

A consciência do tempo através da experiência humana se torna um tema preponderante a partir do século XIX e culmina na angústia da literatura contemporânea. Assim, notamos sua presenga na obra de Manuel Bandeira desde o primeiro livro. Oinua das Horas é publicado em 1917 e já abre com a nota amarga e desesperançada do desenraizamento na vida:

Sou bem nasoido. Menino,

Fui, oomo os demais, felis.

Depois, veio o maid destino

E) fos de mim o que quis.

fase destino, que corta qualquer possibilidade de realiza-

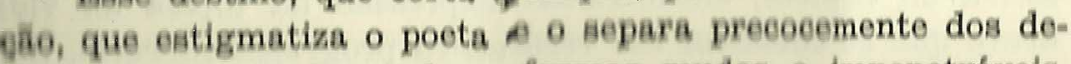
maí meninos, reduz tudo a formal mudal a impenetráveis, quando udesisas horas ardentea / Dieos esta eina fria / = Tata

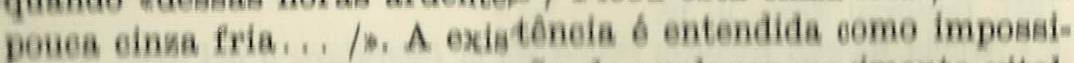
bilidade de realiagede, frustraede de qualquer movimento vital, e o mundo surge como espaço fragmentário, onde não é possível alcançar o entendimento e a compreensão das coisas : «E a vida vai tecendo laços / Quase impossíveis de romper: / Tudo o que amamos / São pedaços / Vivos do nosso próprio ser. /》 Esta apreensão do mundo, que só pode se dar aos pedaços, fragmentàriamente, nos remete de imediato ao universo contemporâneo, tal como o caracteriza o já citado Arnold Hauser - «está lleno de tan profundos antagonismos, y la unidad de su visión de la vida está tan profundamente amenazada, que la combinación de los más remotos extremos, la unificación de las más grandes contradiciones, se convierte en el tema principal, muchas veces el único, de su arte»..$^{3}$ Certamente ocorre a busca de conciliação para os contrários em Cinza das Horas, mas não é possível encontrar a unidade na diversidade; jamais podemos sequer contemplá-la. E, daí, explica-se que imediatamente seja ferida a tópica da vida breve, vazia e absurda, de modo que muito nos aproxima à poesia romântica:

\section{$O$ silêncio é tão largo, tão longo, é tão lento \\ Que dá mêdo... O ar, parado, incomoda, angustia. .. Dir-se-ia que anda no ar um mau pressentimento. (...) \\ O demônio sutil das nevroses enterra \\ A sua agulha de aço no meu crâneo doído. \\ Ouço a morte chamar-me e êsse apêlo me aterra... (...) \\ Já não entendo a vida, e se mais a aprofundo, \\ Mais a descompreendo e não the acho sentido.}

A ameaça da morte tudo reduz àquele punhado de cinza fria e o amor já aqui é entendido por Bandeira como «Fruto sem cuidado / que ainda verde apodreceu». Estamos, então, muito próximos ao desencanto de Ālvares de Azevedo, quando via a sua existência precocemente encerrada e estabelecia a deserenģa em todos os valôres. Mas entre os dois poetas há uma difereng̨a de grau. Para o romintico resta um rofúgio, ainda

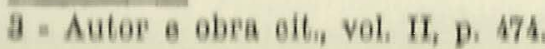


que se trate muito mais de convenção literária da escola do que de uma vivência autêntica. Êle foge para a natureza e, mesmo de dentro do seu deserto interior, pode formular aquela äpiraçăo que finaliza o poema azevediano:

\section{Mas quando preludia ave d'aurora \\ E quando à meia-noite o céu repousa, Arvoredos do bosque, abri os ramos...} Deixai a lua pratear-me a lousa!

1 Im Bandeira, não ocorre o escapismo romântico em direção A natureza, o que acentua ainda mais o sentimento amargo e a perspectiva do absurdo, pois a observação que surge das páfilnas de Ritmo Dissoluto, livro de 1924, é a seguinte:

Nem falta o murmúrio da água, para sugerir, [pela voz dos simbolos,

Que a vida passa! que a vida passa!

F a mocidade vai acabar.

Centamente é em Ritmo Dissoluto e Carnaval que surge o deanfio mais radical no itinerário poético de Bandeira. A sen-

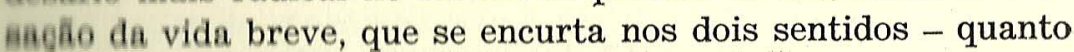
4. ántese na criação de um dos símbolos mais fortes já aparecidos на реевi brasileira: «A Dama Branca que eu encontrei, / Faz iantos anos, / Na minha vida sem lei nem rei, / Sorriu-me em todor os desenganos». E sintomático que a última parte de Carnaval, escrito quando o poeta contava apenas trinta anos, eneerre justamente com um poema intitulado Epílogo.

Eu quis um dia, como Schumann, compor

Um Carnaval todo subjetivo:

Um Carnaval em que o só motivo

Fosse o meu próprio ser interior...

Quando o aeabel $=$ a diferenga que havial $O$ de Behumann é um poema eheie de amor, iil de freseura e de moeldaden:
E o meu tinha a morta morta-côr

Da senilidade e da amargura...

O meu Carnaval sem nenhuma alegria!. .

A existência encontra seu epílogo muito antes de atingir o fim material. Senilidade e amargura são sentimentos que a despojam de qualquer significação e, se materialmente ainda não chegou a têrmo, podemos dizer que já está encerrada do ponto de vista do universo interior do poeta. 4 Instaura-se uma cisão, moderna por excelência, foco motivador de tôda a literatura contemporânea, entre mundo circundante e mundo interior; e, portanto, se estabelece a dicotomia entre um tempo mecânico e um tempo psicológico. O passar das horas, o tempo em sua materialidade, não coincide com a vivência do tempo na interioridade individual. O sentimento do tempo como elemento vazio e destruidor conduz à intuição da ruína iminente. O poema Epílogo deve ser entendido como a expressão de que o passado foi desprovido de significação e o presente é estéril, banhado apenas pela melancolia de recordações perdidas. A presença da Dama Branca traz a idéia da vida que se consome e marca a encruzilhada do universo poético de Manuel Bandeira.

A partir daqui, o caminho percorrido pelo poeta é essencialmente romântico: na impossibilidade de viver o momento presente, sob a certeza de que a vida se esgotou, ou empreende a revalorização do passado ou, em outro caso, a invenção do mundo futuro. Mas isto já não ocorre ao plano do mundo circundante, que morreu definitivamente no Epílogo, e sim ao plano da pura interioridade. O livro seguinte de Bandeira, Libertinagem, de 1930, propõe as duas coordenadas dêste movimento de fuga, superador da realidade contingente. $O$ voltar-se ao passado, que pode ser revocado; ou o voltar-se ao futuro, que pode ser sonhado - imaginificado, para usarmos a terminologia cro-

A. "O pungente sentimento de frustraçăo é, aliás, um de seus temas obsessivos, podendo afetar as formas mais divorsas e dar origom inolu= alve ao tema da evasấo de que 'Vou-mo embora pra Pasárgada' do axemplo olasico", "Gilda a Antonio Candido de Mello a Souza na

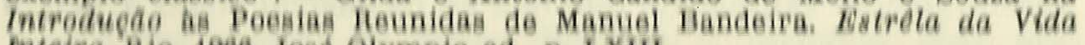
mieira, lilo, 1000, Joad olymple ad, pi LXIII. 
6eana. Assim, êle parte para a revalorização do passado, reeuperando na interioridade a significação de um mundo que existiu outrora e já não pode ser materialmente revivido. O poeta pergunta-se:

Hoje não ouço mais as vozes daquele tempo Minha avó / Meu avô / Totônio Rodrigues / Tomásia / Rosa / Onde estão todos êles?

- Estão todos dormindo

Estão todos deitados

Dormindo profundamente.

Resta pois o retôrno à infância, que só pode ser recuperada ва memória, e empreender a criação de um «novus ordo» - o mundo imaginário em que o passado se faz presente na recorđaลุล๊o, o que é ainda uma maneira de iludir o presente ou tentar a superaçŭo daquela dicotomia entre tempo mecânico e tempo literior que determinara o epílogo. Alcançamos então, com a volta a infancia, a primeira coordenada do movimento de fuga 8 aem história nem literatura / Recife sem mais nada / Recife di minha infância». O poema não possui a estruturação lógica, quase dedutiva, que se evidencia nas composições dos primeiros livros, Constrói-se fragmentàriamente, como fragmentárias são aĭ vivências e recordações do poeta, adaptando-se ao ritmo da memória. Trata-se de organizar «fabulògicamente» o mundo revoeado que se superpõe e substitui o mundo da realidade, poil êste se reduz a «uma pouca cinza fria», enquanto o outro "pareeia impregnado de eternidade». Ao movimentar-se no tempo presente, Bandeira reflete: «Recife. Meu avô morto. Recife mortos. A partir dessa constatação, o movimento poético só pode ocorrer como fuga ao passado. Na temporalidade interior a

A segunda coordenada do movimento de fuga surge ainda em Libertinagem. Sua direọīo ó Pasárgada, agora universo absolutamente fantástieo, que nä̀ as reconstró como o Recife morto mediante a revocação, mas só pode ser concebido ao plano da pura imaginação:

\section{Vou-me embora pra Pasárgada \\ Lá sou amigo do rei \\ Lá tenho a muther que eu quero \\ $\mathrm{Na}$ cama que escolherei \\ Vou-me embora pra Pasárgada.}

A poesia se concebe como refúgio último do poeta, solução decidida nos estritos limites da individualidade que pode temporàriamente (somos tentados a dizer - precàriamente) iludir o sentimento da inutilidade e brevidade conjuntas da vida:

$$
\begin{aligned}
& E \text { quando eu estiver triste } \\
& \text { Mas triste de não ter jeito } \\
& \text { Quando de noite me der } \\
& \text { Vontade de me matar } \\
& \text { - Lá sou amigo do rei - } \\
& \text { Terei a mulher que eu quero } \\
& \text { Na cama que escolherei } \\
& \text { Vou-me embora pra Pasárgada. }
\end{aligned}
$$

Falamos em precariedade na resolução do dilema existencial mediante as duas coordenadas do movimento de fuga, em direção ao passado e ao mundo futuro imaginário. De fato, analisando os livros seguintes de Bandeira, publicados entre 1940 e 1960, cremos esbarrar com outro ponto chave do itinerário poético, que é também uma reviravolta em suas posições. $O$ sentimento da existência precocemente consumida, da senilidade antecipada e do desencanto, retorna com intensidade e parece determinar o abandono da própria atitude de fuga.

$$
\begin{aligned}
& \text { Morrer. } \\
& \text { Morrer de corpo e alma. } \\
& \text { Completamente. }
\end{aligned}
$$

O mesmo grito romântico de Allvares de Azevedo, que já aparecera nos poemal de Ritmo dissoluto e Carnaval. Mas, 貝ur- 
preendentemente - e aqui falamos de reviravolta - a atitude anti-romântica. Está ausente o tom lacrimejante; ausente a tentativa de apegar-se à vida ainda que pela recordação do tempo passado; ausente o desespêro deflagrado na consciência de finitude:

\section{Morrer tão completamente}

Que um dia ao lerem teu nome num papel Perguntem: «Quem foi?»

Morrer mais completamente ainda,

- Sem deixar sequer êste nome.

Atentemos para o título do poema: Morte absoluta. ${ }^{5}$ Vê-se pois que, a esta altura, Bandeira retoma a atitude inicial e motivadors de tôda a sua poesia. Ao final de sua obra, êle compõe, If na Estrela da Tarde, uma peça singular, intitulada Antologia, onde na verdade a estrutura poemática se organiza antològicamente mediante a justaposição de fragmentos das melhores peถุas até aí produzidas. Então, a primeira afirmativa é justamente o retôrno ao sentimento amargo da juventude que êle sentiu esvaziar-se precocemente: «A vida não vale a pena $\mathrm{e}$ a dor de ser vivida». $\mathrm{E}$ isto o afasta definitivamente do mundo da月 recordaçōes do Recife, colocando-o na perspectiva em que o pasiando $\delta$ mesmo irrecuperável e a Pasárgada inatingível, para đạ lugar, tĩo só, a uma constatação que se encerra em si mesma! "Tudo $\delta$ milagre. / Tudo, menos a morte. / Bendita a morte que $\delta$ o fim de todos os milagres». ${ }^{\circ}$

Jâ nถ๊o predomina o sentimento da revolta, nem a tentativa de fuga. Resta o sentimento da resignação mediante a cons-

- Cementa stefan Bacia: "... Bandeira conformou-se com a idéia da merte, que 6 acompanhara durante toda a sua existencia, e agora a vo (1) uma perapeotiva diferente, desejando uma morte tâo completa que

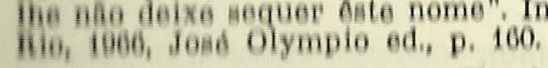

fi : "O vepas, hoja eslebre, 'Wu faço versos eomo quem morro', do

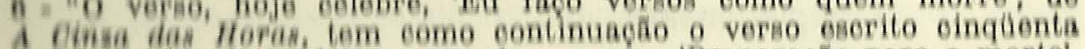

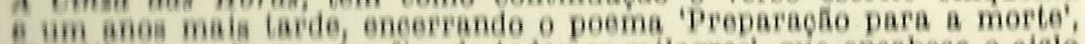

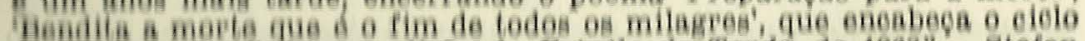

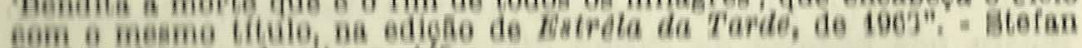

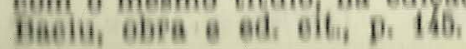

ciência da fugacidade do tempo e da vida. A infância está certamente sepultada e não se pode recuperá-la nem mesmo ao plano da memória. A busca do tempo perdido resulta inútil; e o passado já não se atualiza na revocação:

Teu nome é uma lembrança tão antiga,

Que não tem som nem côr, e eu, miserando,

Não sei mais como o ouvir, nem como o diga.

Falta a morte chegar... Ela me espia

Neste instante talvez, mal suspeitando

Que já morri quando o que fui morria.

As páginas de Estrêla da Tarde trazem finalmente a aceitação da vida que foi breve em suas significações e nos remete ao fecho do ciclo poético em lúcida resignação:

\section{Quando a Indesejada das gentes chegar (...) \\ Encontrará lavrado o campo, a casa limpa, \\ A mesa posta \\ Com cada coisa em seu lugar.}

Chegamos, pois, ao momento presente de um mundo deserto. No entanto, o ato poético projeta o tempo interior por sôbre o tempo mecânico, e o encontro da poesia assinala a passagem do homem criador que imprime sua marca no curso da história. 